\title{
Effect of the COVID-19 Pandemic in German Trauma Centres and Geriatric Trauma Centres DGU
}

\section{Einfluss der COVID-19-Pandemie auf die deutschen TraumaZentren und AltersTraumaZentren DGU}

\author{
Authors \\ Carsten Schoeneberg ${ }^{1}{ }^{\mathbb{D}}$, Daphne-Asimenia Eschbach ${ }^{2}$, Thomas Friess ${ }^{3}$, Sven Lendemans ${ }^{1}$, Christine Hoefer ${ }^{4}$, \\ Steffen Ruchholtz ${ }^{2}$
}

Affiliations

1 Department of Orthopedic and Emergency Surgery, Alfried Krupp Hospital Steele, Essen, Germany

2 Center for Orthopedics and Trauma Surgery, University Hospital Giessen and Marburg, Marburg, Germany

3 Project Coordination Geriatric Trauma Centre, DGU Bochum, Germany

4 AUC, Akademie der Unfallchirurgie GmbH, Munich, Germany

Key words

COVID-19, Centre for Geriatric Trauma, Trauma Centre, IMPACT-Study, proximal femur fracture

Schlüsselwörter

COVID-19, AltersTraumaZentrum, TraumaZentrum, IMPACT-Studie, hüftgelenksnahe Frakturen

published online $\quad 01.02 .2021$

Bibliography

Z Orthop Unfall 2021; 159: 209-215

DOI 10.1055/a-1333-4099

ISSN 1864-6697

(c) 2021. Thieme. All rights reserved.

Georg Thieme Verlag KG, Rüdigerstraße 14,

70469 Stuttgart, Germany

Correspondence

PD Carsten Schoeneberg

Department of Orthopedic and Emergency Surgery,

Alfried Krupp Hospital Steele

Hellweg 100, 45276 Essen, Germany

Phone: 02 01/8 05-1842, Fax: 02 01/8 05-21 83

carsten.schoeneberg@krupp-krankenhaus.de

\section{ABSTRACT}

Background The COVID 19 pandemic is a major challenge to all social systems, particularly the healthcare system. Within an international study, German Trauma Centres DGU and Geriatric Trauma Centres DGU have been questioned about their situation.
Method The questionnaire was translated from English into German and sent to all contacts. The evaluation was performed descriptively.

Results 71 of 692 centres participated in this study. Government instructions to avoid elective treatments have been adhered to by $68 \%$ of the hospitals, and the remaining performed only urgent elective treatments. There was also a decline in the number of traumatological patients. In more than $90 \%$ of the hospitals, only $0-4 \%$ of all patients treated for proximal femur fracture were tested positive for COVID-19. It appears that $84 \%$ of these hospitals have or will have financial deficits. Almost all hospitals were organised and ready to fight the pandemic with their personal and/or infrastructural resources they possess.

Conclusion Our questionnaire shows that the pandemic had an enormous effect on Trauma Centres DGU and Geriatric Trauma Centres DGU. The hospitals expect financial losses. Almost all the hospitals have provided personal and infrastructural resources to be used in the fight against the pandemic with a better outcome in Germany in comparison with international standards.

\section{ZUSAMMENFASSUNG}

Hintergrund Die COVID-19-Pandemie stellt neben den gesellschaftlichen auch eine große Herausforderung für das Gesundheitssystem dar. Im Rahmen einer internationalen Studie wurden die deutschen TraumaZentren DGU und AltersTraumaZentren DGU hierüber befragt.

Methodik Der englische Fragebogen wurde ins Deutsche übersetzt, mit spezifischen Fragen ergänzt und durch die Akademie der Unfallchirurgie an alle Ansprechpartner der Zentren verschickt. Die Auswertung erfolgte rein deskriptiv.

Ergebnisse Es nahmen 71 von 692 Zentren an der Umfrage teil. Die Vorgabe zur Einstellung von elektiven Behandlungen wurde von $68 \%$ der teilnehmenden Kliniken umgesetzt, der Rest führte nur noch dringliche Behandlungen durch. Es zeigte sich auch ein Rückgang unfallchirurgischer Patienten. Tatsächliche COVID-19-Infektionen traten bei über 90\% der Kliniken nur in 0-4\% der behandelten Patienten mit hüftgelenksnaher Femurfraktur auf. Bei $84 \%$ der Kliniken ist ein wirtschaftlicher Schaden für die Klinik eingetreten oder wird erwartet. 
Von fast allen Kliniken wurden personelle oder infrastrukturelle Ressourcen zur Bekämpfung der Pandemie bereitgestellt.

Schlussfolgerung Unsere Umfrage zeigt, dass die Pandemie einen starken Einfluss auf die TraumaZentren DGU und AltersTraumaZentren DGU hat. Die Kliniken erwarten wirtschaftli- che Einbußen. Fast alle Kliniken stellten aber personelle und infrastrukturelle Ressourcen zur Bekämpfung der Pandemie bereit und leisteten so einen Beitrag für den bisher guten Pandemieverlauf in Deutschland im internationalen Vergleich.

\section{Introduction}

On 11 March 2020 the World Health Organization declared a pandemic caused by the novel Coronavirus-2 (COVID-19) [1]. The COVID-19 pandemic represents a major challenge for all healthcare systems worldwide. The lockdown in Germany from 13 March to 19 April meant massive restrictions on both public life and routine clinical operations. Federal Health Minister Spahn declared that, starting on 16 March 2020, all hospitalisations and surgeries without medical urgency were to be postponed. It was not until a further government statement was issued on 27 April 2020 that some of the available hospital capacity could once again be used for elective surgeries. As a result, a current study based on data from the Initiative for Quality Medicine (IQM) showed a pronounced reduction in numbers of hospital treatments for certain diagnoses [2]. Orthopaedic medicine in particular, with therapies and surgeries that are for the most part elective, registered a sharp reduction in these procedures. During this period, $78.3 \%$ fewer hip arthroplasties and $83.5 \%$ fewer knee arthroplasties were implanted. Trauma surgeries also showed a downturn. 34\% fewer polytraumata, $24.1 \%$ fewer femur neck fractures and $18.9 \%$ fewer pertrochanteric femur fractures were treated [2]. In a current survey, all members of the University Orthopaedic and Trauma Surgery Professors Convention were asked for their assessment of the impact of the COVID-19 pandemic. The replies reported a reduction of hospital bed capacities by $45.3 \pm 20.1 \%$, a reduction of surgical capacities by $49.4 \pm 20.4 \%$ and fewer emergency patients by $72.0 \pm 21.1 \%$. In the university clinical departments, $14.7 \pm 17.2 \%$ of the medical employees were reassigned to other departments. The average financial loss of the departments was reported as $29.3 \pm 17.9 \%$ [3].

Within the framework of the international study "International Multicentric Project Auditing COVID-19 in Trauma \& Orthopaedics (IMPACT)", initiated by the Scottish Orthopaedic Research Trust into Trauma, the Scottish Hip Fracture Audit and the Scottish Government, the study initiators contacted the Trauma Surgery Academy (AUC) so as to involve Germany in the study. A cooperation was agreed on within a partial study, the IMPACT Services Survey. The aim of this partial study was to evaluate the impact of the COVID-19 pandemic on elective treatments in orthopaedics and trauma surgery, the impact on treatment of proximal femur fractures, the strategies aimed at containing the pandemic and the subsequent normalisation phase. To this end, the English questionnaire was translated into German and supplemented with specific questions. This constituted a restriction on free formulation of the survey questionnaire on our part so as to comply with the parameters of the international study. Publication of the international survey results is planned by the IMPACT study initiators.
The aim of this study, besides cooperation with the efforts of the IMPACT study, was to determine the impact of the COVID-19 pandemic on trauma surgery in Germany at all medical care levels.

\section{Material and Methods}

The initiators of the international IMPACT study provided the questionnaire used in the survey to the AUC [4]. The authors translated the questionnaire into German and supplemented it with additional questions so as to obtain further details on levels of care and therapy of other diagnoses. The questionnaire comprised a total of 24 questions. The first two questions concerned the organisational structure of the clinic, which German State it was located in and the TraumaZentrum DGU (TZ) (Trauma Centre) classification (local/regional/supraregional) or whether certification as an AltersTraumaZentrum DGU (ATZ) (Geriatric Trauma Centre) had been issued. The next five questions referred to the general and organisational impact of the COVID-19 pandemic.

The following 14 questions addressed the impact of the COVID-19 pandemic on treatment of special diagnoses. Specifically, effects on fractures close to the hip joint, distal radius fractures, proximal humerus fractures and on the treatment of polytraumatised patients were addressed. Replies were subgrouped in each case by month for March, April and May 2020 and participants were asked to draw comparisons with the same monthly periods in the previous year.

The next question referred to the recovery phase and expected long-term impacts of the COVID-19 pandemic. The last two questions were designed to determine whether the figures provided were estimates or concrete data and whether the participants had any further comments on the COVID-19 pandemic.

It was left up to the participants whether they wished to fill out the questionnaire anonymously or enter their personal data for possible citation in the study group of the IMPACT study.

The AUC passed on the survey in the form of an online questionnaire to the TZ and ATZ contacts as listed, whereby several questions were labelled as mandatory, i.e. the form could not be completed unless these questions were answered.

The web-based survey started on 20 June 2020 and concluded on 10 July 2020. The feasible survey period was short as stipulated by the IMPACT study initiators.

The replies from the participating clinics were then evaluated using the program Microsoft Excel. The results formulations were purely descriptive, with only mean values and categories reported. 


\section{Vergleich Zertifizierte Traumzentren und Antwort Rücklauf}

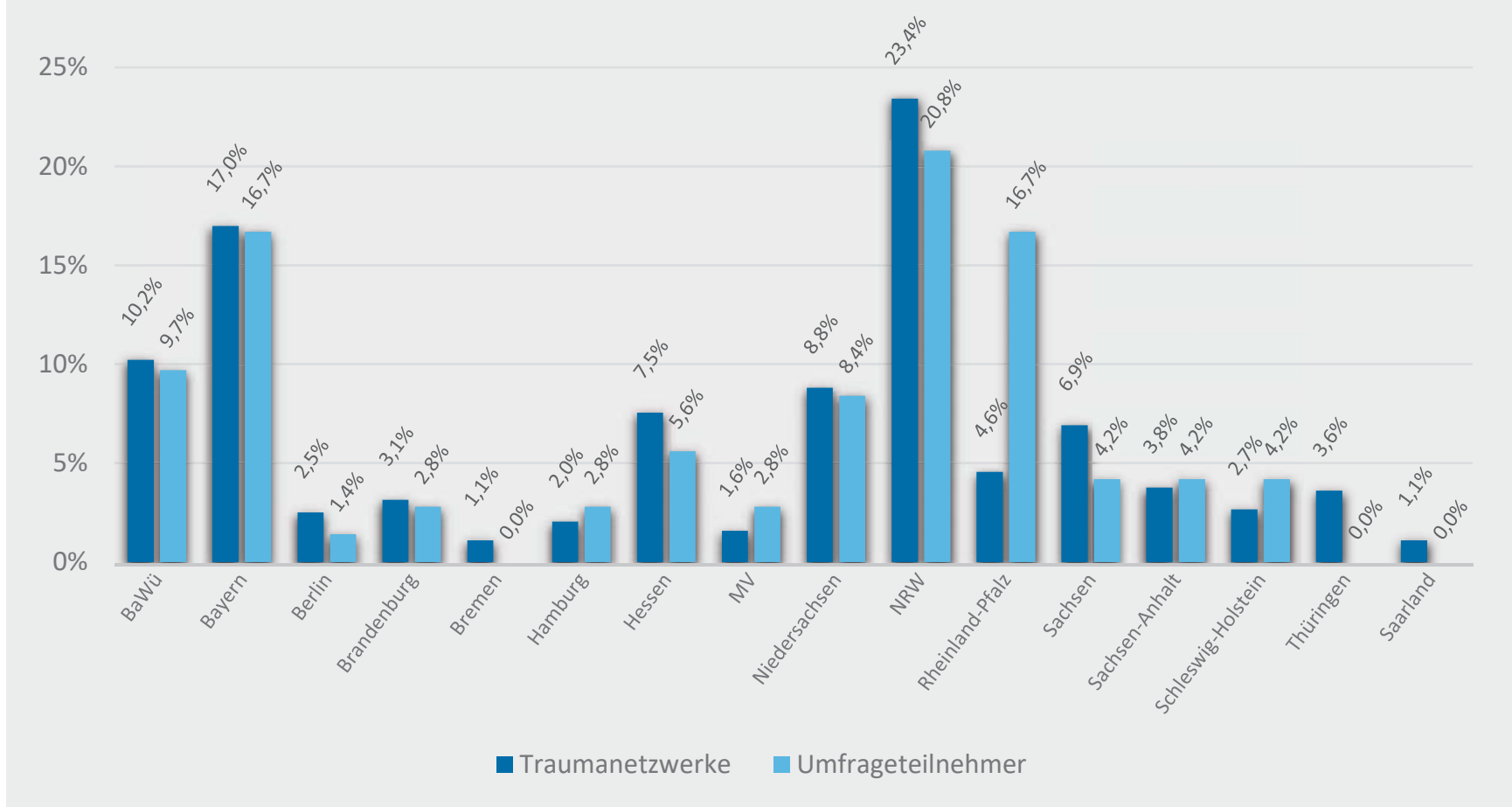

- Fig. 1 Comparison of regional distribution of TraumaZentren DGU with location of clinics of the survey respondents. No reports from Bremen, Thuringia and Saarland; BaWü: Baden-Württemberg; MV: Mecklenburg-Vorpommern; NRW: North Rhine-Westphalia.

\section{Results}

72 centres of the total of 692 queried participated in the survey, a response rate of $10.4 \%$. $76.4 \%$ of these respondents were combined orthopaedic and trauma surgery clinics and $23.6 \%$ were trauma surgery facilities only. - Fig. 1 shows the distribution among the individual Federal German States.

In terms of care level classification $45.8 \%$ of the participating clinics were certified as local TZs, $30.6 \%$ as regional TZs and $19.4 \%$ as supraregional TZs, reflecting the distribution in the TraumaNetzwerk DGU (Trauma Network) (49.7\%/32.9\%/17.5\%). $33.3 \%$ of the participating clinics were certified as ATZs ( $\bullet$ Fig. 2).

$58.3 \%$ of respondents reported a qualitative downturn in trauma surgery/orthopaedic medical care due to the COVID-19 pandemic. $38.9 \%$ saw no impact. Only $19.4 \%$ had access to full surgical capacity during the lockdown phase. $43.1 \%$ of respondents had access to $50 \%$ of normal capacity ( $\bullet$ Table 1 ). Notwithstanding, $59.7 \%$ had already registered a normalisation of capacities. A total of $84.7 \%$ of the clinics reported reduced numbers of surgeries.

Personnel had to be reassigned to support pandemic measures in about $70 \%$ of the responding clinics, with areas reallocated for these reasons in $76.4 \%$ ( $\triangleright$ Table 1 ).

In March 2020, 40.3\% of the clinics registered a decrease in proximal femur fractures by an average of $35 \%$ per clinic compared to March 2019. 54.2\% of clinics reported no change. The number of clinics reporting a decrease was still 33.3\% for April 2020 (with 61.1\% reporting no change). Further normalisation was then reported for May 2020 with $18.1 \%$ still showing reduced case numbers compared to the previous year (and no changed reported in 75\%). These clinics did, however, report a mean decrease by $38 \%$ ( $\triangleright$ Table 2 ).

The incidence of patients with proximal femur fractures who tested positive for COVID-19 was mainly within the range of 0 $4 \%$ ( Fig. 3).

Regarding indications for surgical therapy, $94 \%$ of the participating facilities reported no shift towards more conservative therapy.

Regarding elective orthopaedic/trauma surgery therapy, $68.1 \%$ reported that it had been completely discontinued and the rest continued to perform only urgent elective therapies, including those potentially involving surgery. $83.3 \%$ reported no impact on therapy of tumour diseases due to discontinuation or reduction of the elective programme, but even this therapeutic indication saw reduced treatment in $16.7 \%$ of these facilities. At any rate, discontinuation of the elective programme did result in a pronounced reduction in admissions, especially to orthopaedic/ trauma surgery wards. $84.7 \%$ reported this situation. Several respondents remarked in the freely formulated responses that the compensation payments passed by the Federal Government would not cover the resulting losses. In $94.4 \%$ of the clinics, the 


\section{Verteilung Zertifizierungen}

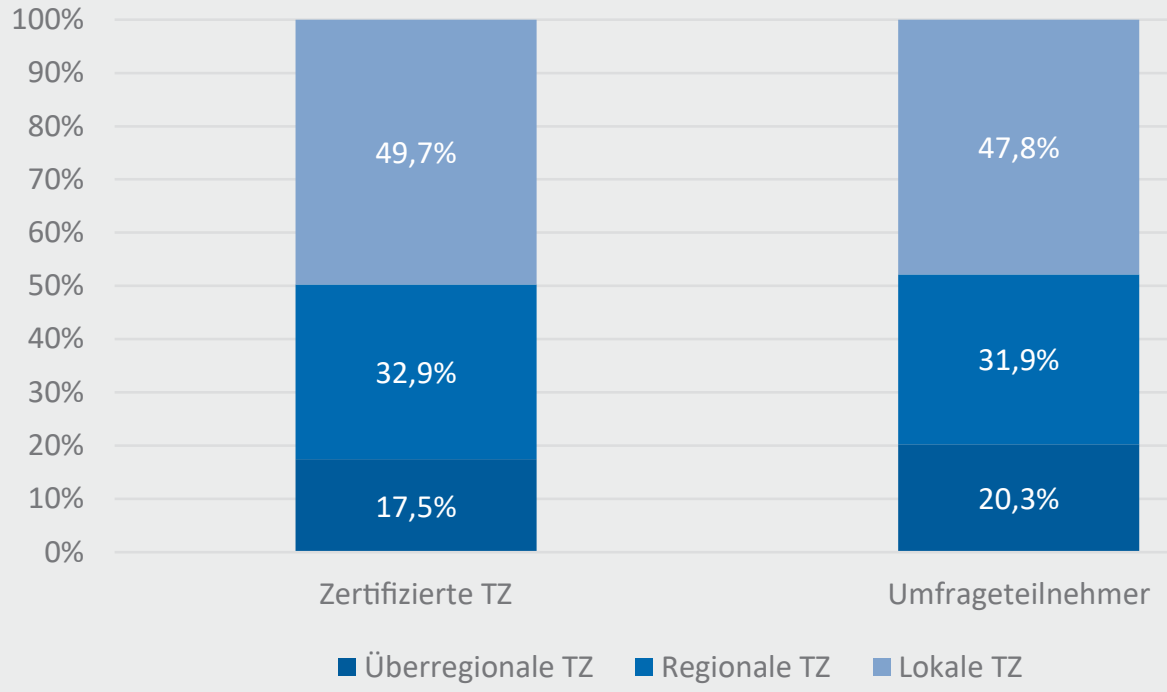

- Fig. 2 Percentile distribution of the different levels of care in TraumaNetzwerk DGU and among the survey respondents. The distribution is comparable in the two groups.

elective programme had already been reinstated. $90.3 \%$ also reported that this situation was not worrisome.

With regard to therapy of polytraumatised patients with Injury Severity Scores $\geq 16$, the data from March and April 2020 showed a comparable decrease compared to the same period in the previous year in about $50 \%$ of the clinics. In May 2020, the responding clinics still reported a decrease in case numbers of $30.6 \%$ ( $\triangleright$ Table 2 ).

The same tendency was observed in the numbers of treated cases of distal radius fracture. A decrease was still reported for March and April by $40-45 \%$ of the clinics, which figure was still at $33.3 \%$ in May 2020 ( $\vee$ Table 2). An interesting aspect was that in $16.7 \%$ of the clinics the indication for surgical therapy was revised, i.e. more patients then received conservative therapy in these clinics. This was often justified as requested by patients due to a fear of COVID-19 infection.

The decrease for proximal humerus fractures was somewhat less pronounced. In this category, $34.7 \%$ of clinics reported a decrease for March and April 2020, with 29.2\% still reporting this for May 2020 ( $\triangleright$ Table 2). As regards the diagnosis of a proximal humerus fracture, $93.1 \%$ reported no change regarding indications for surgical therapy. Only a small number of clinics reported having treated a larger portion of humerus fractures conservatively.

In their replies regarding the questions on the recovery phase and long-term effects of the COVID-19 pandemic, many clinics stated that they did not expect any more serious impacts. A total of 30 clinics feared financial losses, 9 expanded organisational demands, 4 personnel cuts and 2 reductions in advanced training programmes. The reported potentially positive effects were improved hygienic standards (3 clinics), reduction in overtime hours worked (6 clinics), procedural improvements ( 9 clinics) and remuneration for empty-bed capacities (2 clinics). The numeric data reported in the survey were based on estimates in $80.6 \%$ of respondents and on actual concrete information in the rest.

\section{Discussion}

Our survey reflects the development of orthopaedic and trauma surgery medical practice in Germany as impacted by the COVID19 pandemic in all care level classifications. The analysis was based on categorisation of the trauma centres as local/regional or supraregional. Regarding elective procedures in particular, the decrease was dramatic. About $70 \%$ of the clinics discontinued their elective programmes completely, while the remainder continued to perform only urgent elective therapies. This result was confirmed by the analysis of the IQM data done by Kuhlen et al., describing a decrease in arthroplasties by more than $80 \%$ and in spinal procedures by nearly 55\% [2]. The Diagnosis Related Groups (DRG) browser of the Hospital Remuneration System Institute (InEK) also recorded a decrease in elective knee endoprosthetic procedures by $52.5 \%$ (DRG 144C) and in hip endoprosthetic procedures by $48 \%$ (DRG 147C) [5]. These effects, especially on elective orthopaedics and trauma surgery, had also been described at the international level $[6,7]$.

Our survey also revealed that trauma surgery therapies decreased during the COVID-19 lockdown as well. Nearly $50 \%$ of the clinics reported having treated fewer cases of proximal femur fractures during the lockdown. The literature, however, reports that in particular the numbers of fragility-related proximal femur fractures had remained constant, even during the pandemic [8- 
- Table 1 Measures taken and reallocations of personnel and infrastructure resources.

\begin{tabular}{|c|c|c|c|c|c|c|}
\hline Question & \multicolumn{6}{|c|}{ Response choices: Percentiles } \\
\hline \multirow{2}{*}{$\begin{array}{l}\text { Capacity: } \\
\text { Availability of surgi- } \\
\text { cal theatres until } \\
\text { normalisation } \\
(\mathrm{n}=72)\end{array}$} & $>100 \%$ & $100 \%$ & $75 \%$ & $50 \%$ & \multicolumn{2}{|l|}{$\leq 25 \%$} \\
\hline & $4.2 \%$ & $19.4 \%$ & $27.8 \%$ & $43.1 \%$ & $5.5 \%$ & - \\
\hline \multirow{2}{*}{$\begin{array}{l}\text { Normalisation in } \\
(n=42)\end{array}$} & 1st half of April & 2nd half of April & 1st half of May & 2nd half of May & 1st half of June & 2nd half of June \\
\hline & $4.9 \%$ & $0.0 \%$ & $19.5 \%$ & $19.5 \%$ & $53.7 \%$ & $2.4 \%$ \\
\hline \multirow[t]{2}{*}{$\begin{array}{l}\text { Reassigned } \\
\text { personnel } \\
(\mathrm{n}=49)\end{array}$} & $\begin{array}{l}\text { Medical special- } \\
\text { ists }\end{array}$ & $\begin{array}{l}\text { Medical assis- } \\
\text { tants }\end{array}$ & $\begin{array}{l}\text { Students in } \\
\text { probationary } \\
\text { year }\end{array}$ & $\begin{array}{l}\text { Qualified nurses } \\
\text { Surgical/technical } \\
\text { assistants }\end{array}$ & $\begin{array}{l}\text { Orthogeriatric } \\
\text { employees }\end{array}$ & $\begin{array}{l}\text { Assistant nurs- } \\
\text { ing personnel }\end{array}$ \\
\hline & $38.8 \%$ & $79.6 \%$ & $18.4 \%$ & $79.6 \%$ & $14.3 \%$ & $71.4 \%$ \\
\hline \multirow[t]{2}{*}{$\begin{array}{l}\text { Reallocated areas } \\
(n=55)\end{array}$} & Entire ward & Ward sections & $\begin{array}{l}\text { Surgical } \\
\text { theatres }\end{array}$ & Examination rooms & $\begin{array}{l}\text { Emergency } \\
\text { admissions }\end{array}$ & \multirow[t]{2}{*}{-} \\
\hline & $7.3 \%$ & $80.0 \%$ & $27.3 \%$ & $34.5 \%$ & $47.3 \%$ & \\
\hline \multirow[t]{2}{*}{$\begin{array}{l}\text { Covid-19 measures } \\
\text { taken } \\
(\mathrm{n}=66)\end{array}$} & $\begin{array}{l}\text { Symptom ques- } \\
\text { tionnaire }\end{array}$ & $\begin{array}{l}\text { Obligatory lab- } \\
\text { oratory test }\end{array}$ & $\begin{array}{l}\text { Laboratory test } \\
\text { in case of con- } \\
\text { spicuous history }\end{array}$ & Other & Unknown & \multirow[t]{2}{*}{-} \\
\hline & $74.2 \%$ & $48.5 \%$ & $54.5 \%$ & $6.1 \%$ & $0.0 \%$ & \\
\hline
\end{tabular}

- Table 2 Percentile distribution of data reported by clinics for changes in case numbers for the diagnoses surveyed and compared to the same month in the previous year.

\begin{tabular}{|c|c|c|c|c|}
\hline & Hip fracture & Polytrauma & $\begin{array}{l}\text { Distal radius } \\
\text { fracture }\end{array}$ & $\begin{array}{l}\text { Humerus head } \\
\text { fracture }\end{array}$ \\
\hline \multicolumn{5}{|l|}{ March 2020} \\
\hline - Decrease & $40.3 \%$ & $48.6 \%$ & $40.3 \%$ & $34.7 \%$ \\
\hline - Mean decrease/clinic & $35 \%$ & $39 \%$ & $31 \%$ & $39 \%$ \\
\hline - No change & $54.2 \%$ & $50.0 \%$ & $54.0 \%$ & $63.9 \%$ \\
\hline - Increase & $5.5 \%$ & $1.4 \%$ & $5.7 \%$ & $1.4 \%$ \\
\hline \multicolumn{5}{|l|}{ April 2020} \\
\hline - Decrease & $33.3 \%$ & $47.2 \%$ & $45.8 \%$ & $34.7 \%$ \\
\hline - Mean decrease/clinic & $39 \%$ & $39 \%$ & $32 \%$ & $43 \%$ \\
\hline - No change & $61.1 \%$ & $48.6 \%$ & $48.6 \%$ & $62.5 \%$ \\
\hline - Increase & $5.6 \%$ & $4.2 \%$ & $5.6 \%$ & $2.8 \%$ \\
\hline \multicolumn{5}{|l|}{ May 2020} \\
\hline - Decrease & $18.1 \%$ & $30.6 \%$ & $33.3 \%$ & $29.2 \%$ \\
\hline - Mean decrease/clinic & $38 \%$ & $45 \%$ & $17 \%$ & $37 \%$ \\
\hline - No change & $75.0 \%$ & $61.1 \%$ & $59.7 \%$ & $70.8 \%$ \\
\hline - Increase & $6.9 \%$ & $8.3 \%$ & $7.0 \%$ & $0.0 \%$ \\
\hline
\end{tabular}

10]. These international results were not confirmed for Germany, either by our survey or by the IQM data, with a reduction of femur neck fractures by about $24 \%$ and of trochanteric femur fractures by about 19\% [2]. Data from the InEK DRG browser revealed a reduction from 41,975 proximal femur fractures during the period from 01 March 2019 to 31 May 2019 to 33,753 cases, a reduction by about $20 \%$ [5]. This could reflect differences in German, Spanish and English data for unknown reasons. The first part of the IMPACT study, a multicentre, retrospective evaluation of 30day mortality post femur fracture close to the hip joint and COVID-19 infection, also reported no reduction in incidence of femur fractures close to the hip joint during the pandemic [11]. An 


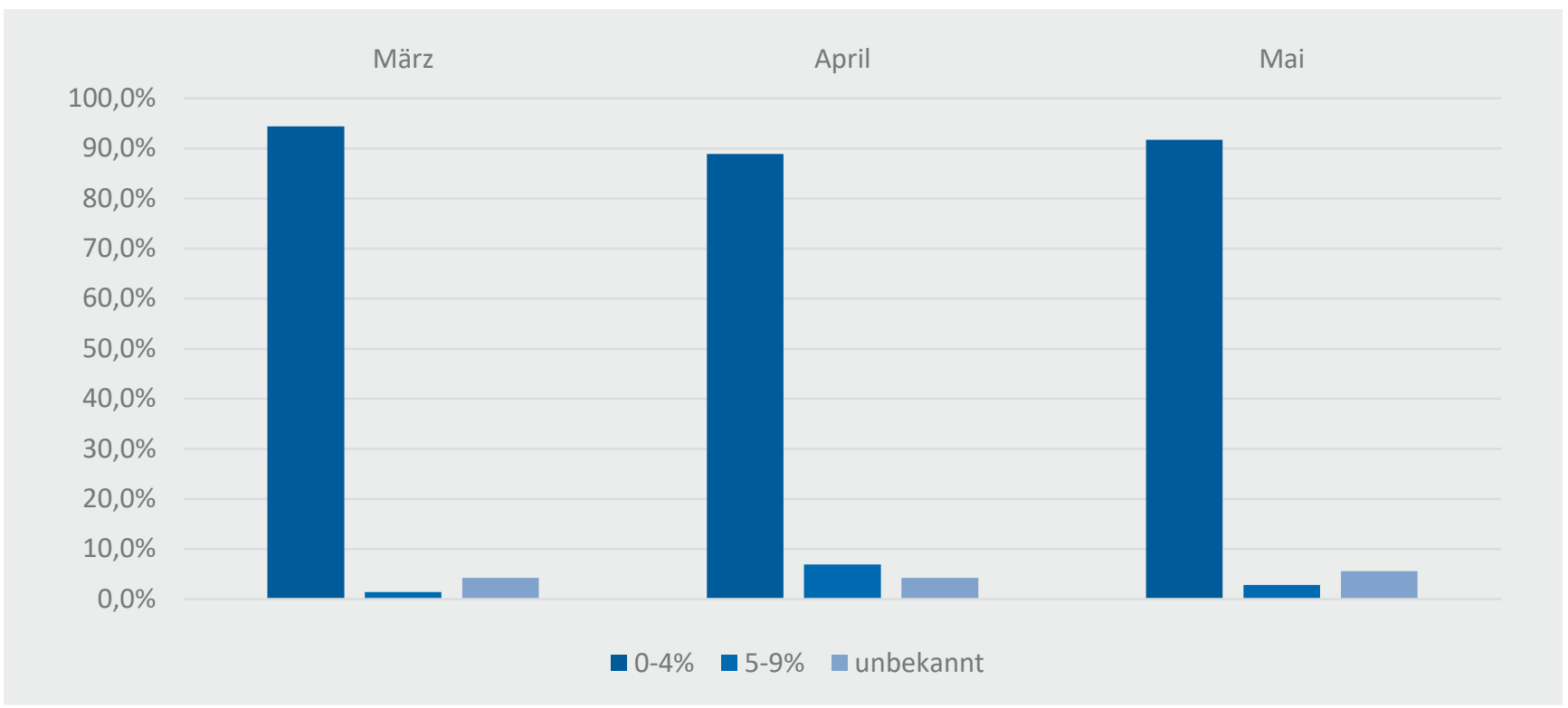

- Fig. 3 Percentile of patients who tested positive for COVID-19 in the total collective of fractures close to the hip joint.

interesting aspect of the first results from the IMPACT study was the proportion of COVID-19-positive patients, which was $8.5 \%$ of all patients treated during the study period [10]. In our survey, the percentage of COVID-19-positives from March to May 2020 was $0-4 \%$ in about $90 \%$ of the clinics. A possible explanation for the divergent data could be that all patients in the IMPACT study were tested and only $26 \%$ of the patients showed relevant symptoms upon admission [10].

As to developments in polytraumata, distal radius fractures and proximal humerus fractures, international publications report a similar picture. A monocentric epidemiological study at a U.K. hospital also determined a clear reduction of polytraumata and fractures of the upper extremity [12]. This is explained in particular by massive restrictions on public life in the lockdown, resulting in pronounced reduction of injuries, particularly those due to sporting activities, alcohol abuse and traffic accidents [13]. According to the Federal Office of Statistics, traffic accidents decreased during the period from January to April 2020 by $18.4 \%$ compared to the same period in the previous year. The rate dropped by $35 \%$ in April alone [14]. A pronounced reduction by $10.3 \%$ was also reported for reportable occupational and commuting accidents by the Transport and Traffic Professional Association for the 1st quarter of 2020 [15]. On the other hand, the Professional Association of the Construction Industry expressed concern about increased death rates due to construction site accidents during the COVID-19 pandemic [16]. One clinic in our survey reported a significant reduction in patient numbers from a German holiday resort area due to the drop-off in tourism. Reports from North America also mentioned lower incidence levels for polytraumata and other injuries, which was, however, paralleled by a rise in penetrating wounds caused by firearms [17]. The InEK DRG browser revealed a decrease from 15273 proximal humerus fractures in 2019 to 12145 cases, a reduction by $20.5 \%$. Case numbers for polytraumata decreased from 1919 to 1485 cases (reduction by $20.6 \%$ ). Distal radius fracture treatments dropped from 18527 cases to 16797 (reduction by 9.3\%). The period from 01 March 2019 to 31 May 2019 was compared to the period from 01 March 2020 to 31 May 2020 in each category [5]. On the whole, the reductions in case numbers observed by the responding clinics were comparable to the data provided to the InEK by all German clinics.

A considerable share of the personnel and infrastructure resources of the clinics was used in the fight to contain the pandemic. Compared to results of the survey of the members of the University Orthopaedic and Trauma Surgery Professors Convention, the share would appear to be even higher. In the study by Haffer et al., the initially somewhat low quota was explained by the fact that university departments are responsible for research and teaching tasks in addition to patient treatments [3]. However, the respondents to the present survey were for the most part clinics without university affiliation.

$84.7 \%$ of the clinics reported palpable drops in clinic revenues due to the COVID-19 pandemic, this despite the compensation payments passed by the Federal government [18]. This was confirmed in a retrospective study at a Germany University Clinic for Orthopaedics and Trauma Surgery. In addition to the clear reduction in case numbers, this study showed a loss of financial revenues of about $57 \%$ after all compensations were included. These medical facilities calculated a mean shortfall, despite correction for material costs, of $567 €$ per case. This study compared the period from 16 March 2020 to 17 April 2020 with the exact same period in the previous year [19].

The most important limitation of our study is certainly the low response rate, which entails a high risk of bias. However, the percentile distribution of care levels in the trauma centres is comparable to the actual distribution in Germany and can thus presumably give a realistic picture. In addition, most of the estimates were made by senior physicians in the respective clinics. Estima- 
tion of the figures used here must also be mentioned as a clear limitation.

Nonetheless, the results of our survey did demonstrate that German orthopaedic and trauma surgery clinics responded at all care levels to the political call to discontinue nearly the entire elective programme during the lockdown. In addition to this, orthopaedic and trauma surgery clinics provided resources and reassigned personnel successfully in support of the effort to contain the COVID-19 pandemic.

\section{Conclusion}

Our survey revealed a significant impact of the COVID-19 pandemic on the TraumaZentren DGU and AltersTraumaZentren DGU. Besides the clear reduction of elective patient therapies, this fact is also reflected in many clinics in decreases in the numbers of trauma surgery patients with fractures. This can be explained by the lockdown and its restrictions on public life. It also explains the fear of economic sacrifices felt by most of the responding clinics.

\section{Conflict of Interest}

The authors declare that they have no conflict of interest.

\section{References}

[1] World Health Organization. WHO Director-General's opening remarks at the media briefing on COVID-19. Online (Accessed: 01.10.2020): https://www.who.int/dg/speeches/detail/who-director-general-s-opening-remarks-at-the-media-briefing-on-covid-19-11-march-2020

[2] Kuhlen R, Winklmair C, Schmithausen D et al. The effects of the COVID19 pandemic and lockdown on routine hospital care for other illnesses. Dtsch Arztebl Int 2020; 117: 488-489. doi:10.3238/arztebl.2020.0489

[3] Haffer H, Schömig F, Rickert M et al. Impact of the COVID-19 Pandemic on Orthopaedic and Trauma Surgery in University Hospitals in Germany: Results of a Nationwide Survey. J Bone Joint Surg Am 2020. doi:10.2106/ JBJS.20.00756

[4] IMPACT Collaborative Research. IMPACT Services Survey. Online (Accessed: 01.10.2020): https://www.surveymonkey.co.uk/r/IMPACT_Hip_ Survey

[5] Institut für das Entgeltsystem im Krankenhaus (InEK). InEK DatenBrowser. Im Internet (Stand: 01.10.2020): https://datenbrowser.inek. org/

[6] Jenkins P. The Early Effect of COVID-19 on Trauma and Elective Orthopaedic Surgery. 17. April 2020. Online (Accessed: 01.10.2020): https:// www.boa.ac.uk/resources/knowledge-hub/the-early-effect-of-covid19-on-trauma-and-elective-orthopaedic-surgery.html
[7] Oussedik S, Zagra L, Shin GY et al. Reinstating elective orthopaedic surgery in the age of COVID-19. Bone Joint J 2020; 102-B: 807-810. doi:10.1302/0301-620X.102B7.BJJ-2020-0808

[8] Nuñez JH, Sallent A, Lakhani K et al. Impact of the COVID-19 Pandemic on an Emergency Traumatology Service: Experience at a Tertiary Trauma Centre in Spain. Injury 2020; 51: 1414-1418. doi:10.1016/j.injury.2020.05.016

[9] Kayani B, Onochie E, Patil V et al. The effects of COVID-19 on perioperative morbidity and mortality in patients with hip fractures. Bone Joint J 2020; 102-B: 1136-1145. doi:10.1302/0301-620X.102B9.BJJ-20201127.R1

[10] Hall A], Clement ND, Farrow L et al. IMPACT-Scot report on COVID-19 and hip fractures. Bone Joint J 2020; 102-B: 1219-1228. doi:10.1302/ 0301-620X.102B9.BJJ-2020-1100.R1

[11] Zhu Y, Chen W, Xin X et al. Epidemiologic characteristics of traumatic fractures in elderly patients during the outbreak of coronavirus disease 2019 in China. Int Orthop 2020; 44: 1565-1570. doi:10.1007/s00264020-04575-0

[12] Scott CEH, Holland G, Powell-Bowns MFR et al. Population mobility and adult orthopaedic trauma services during the COVID-19 pandemic: fragility fracture provision remains a priority. Bone Jt Open 2020; 1: 182189. doi:10.1302/2046-3758.16.BJO-2020-0043.R1

[13] Sahagun L. Coronavirus Stay-At-Home Orders that Went into Effect on March 20 Have Reduced Vehicle Collisions on California Roadways by Roughly the Half. Online (Accessed: 01.10.2020): https://www.latimes. com/environment/story/2020-04-01/coronavirus-stay-at-home-ordershave-reduced-traffic-accidents-by-half

[14] Statistisches Bundesamt. 35\% weniger Straßenverkehrsunfälle im April 2020 im Vergleich zum Vorjahr. Zahl der Verkehrstoten nahezu unverändert. Pressemitteilung Nr. 221 vom 19. Juni 2020. Online (Accessed: 01.10.2020): https://www.destatis.de/DE/Presse/Pressemitteilungen/ 2020/06/PD20_221_46241.html

[15] Berufsgenossenschaft Verkehr. Arbeits- und Wegeunfälle: Rückläufiger Trend. Online (Accessed: 01.10.2020): https://www.bg-verkehr.de/medien/news/2020/ausgabe-8-2020/aktuell/arbeits-und-wegeunfaelle-ruecklaeufiger-trend

[16] Berufsgenossenschaft BAU. Alarmierende Zahlen am Bau: Tödliche Arbeitsunfälle deutlich angestiegen. Online (Accessed: 01.10.2020): https://www.presseportal.de/pm/60172/4591024

[17] Qasim Z, Sjoholm LO, Volgraf J et al. Trauma center activity and surge response during the early phase of the COVID-19 pandemic - the Philadelphia story. J Trauma Acute Care Surg 2020; 89: 821-828. doi:10.1097| TA.0000000000002859

[18] Bundestag. Gesetz zum Ausgleich COVID-19 bedingter finanzieller Belastungen der Krankenhäuser und weiterer Gesundheitseinrichtungen (COVID-19-Krankenhausentlastungsgesetz). Bundesgesetzblatt Teil I: 580. Online (Accessed: 01.10.2020): https://dejure.org/ext/ 3e8909b7fa5c1d262058c675bd94d981

[19] von Dercks N, Körner C, Heyde C-E et al. Wie stark trifft die Corona-Pandemie die Kliniken für Orthopädie und Unfallchirurgie? Eine Analyse der ersten 5 Wochen. Orthopäde 2020; 49: 494-501. doi:10.1007/s00132020-03926-4 